\title{
Study on Major Causes of Equine Colic at the Donkey Sanctuary and SPANA Clinic in Bishoftu Town
}

\section{Birtukan Tadesse ${ }^{1}$ and Birhanu Abera ${ }^{2^{*}}$}

${ }^{1}$ Adaba District Livestock and Fishery Resource Development office, Ethiopia

${ }^{2}$ Asella Regional Veterinary Laboratory, PO Box: 212, Asella, Ethiopia

"Corresponding author: Birhanu Abera, Asella Regional Veterinary Laboratory, PO Box: 212, Asella, Ethiopia, Tel: +0913333944; E-mail: birhanuabera27@yahoo.com

Rec date: December 05, 2017; Acc date: January 08, 2018; Pub date: January 10, 2018

Copyright: (C) 2018 Tadesse B, et al. This is an open-access article distributed under the terms of the Creative Commons Attribution License, which permits unrestricted use, distribution, and reproduction in any medium, provided the original author and source are credited.

\begin{abstract}
A case series study was conducted between December 2009 and April 2010 at the donkey sanctuary and SPANA clinics in Bishoftu town to determine the major causes of equine colic. During the study period a total of $121(9.1 \%)$ episodes of colic were recorded in a population of 1336 equine ( 800 horses, 500 donkeys and 36 mules). From the total cases $93(11.6 \%)$ and $28(5.6 \%)$ were horses and donkeys, respectively. No mule was observed with colic problem. The proportion of colic cases in horses was significantly $(p=0.0003)$ higher than that of donkeys. The major risk factors found associated with colic were feed change, parasite infestation and poor deworming history, enteroliths, heavy work, age and dental abnormalities $(P<0.05)$ in the cases. Physical and clinical examination of the colic cases showed elevated respiratory and pulse rates, congested mucous membrane, increased mean of PVC-value, decreased appetite, abdominal distension, poor body condition, intermittent and continuous abdominal pain and dullness. Donkey were more commonly affected with impaction colic $(78.6 \%)$ and less commonly with flatulent colic $(21.4 \%)$. The most important colic identified in horses was spasmodic colic $(66.7 \%)$ followed by impaction colic $(25.8 \%)$ and undefined colic $(7.6 \%)$. In conclusion, improving feeding management, implementing parasite control strategies and raising the awareness of the owners of equids are needed in order to prevent the impact of the diseases on equine production.
\end{abstract}

Keywords: Colic; Donkey sanctuary; Equine; Risk factor; SPANA

\section{Introduction}

Ethiopia has about 10.3 million equine that means, there are about 2.8 million horses, 7.8 million donkeys, and 0.4 million mules hosted by varieties of agro climatic zone [1]. There is one equine for every four people in the agricultural sector and for every five person of the total population. Low level of development of road transport network and rough terrain of the country make the donkey the most valuable, appropriate and affordable pack animals under small holder farming system of Ethiopia [2]. Horses are more populated in the highland while mules and donkeys in middle and low altitudes of the country. Horses, donkeys and mules are serving as a major means of transporting agricultural products and different items in developing countries [3]. Among the major problems working equines, colic is the first killer disease [4].

Equine colic, a disorder manifested in abdominal pain is the most frequent cause of emergency treatment and death in horse [5]. Intestinal disturbance also characterized by altered motility patterns such as anterior enteritis, and colonic impaction [6]. Colic is the single most common and serious equine emergency recognized nationally and internationally. Even in the 21st century, the number one killing disease of horses continues to be colic. Colic accounts for more equine deaths, noted by equine insurance companies, than any other disease. That serious concern affecting the welfare and survival of donkey at donkey sanctuary in the UK. One of the most reported causes is due to impacted ingest in the large intestine (Impaction colic) [7].

Diet, especially grain feeding and recent dietary changes has been identified by epidemiological development of colic and laminitis, both major causes of equine mortality [4]. Prognosis of most animal with impaction of large colon recovers completely, if the condition is diagnosed early and treatment initiated promptly. Impactive colic, spasmodic colic, intussusceptions, volvulus, torsion, etc. are common causes of colic [8]. A range of anatomic and functional factors of the gastrointestinal tract also can predispose horse to colic [3]. Although closely related, there are important differences in physiology and behavior between the donkey and horse that influence the presenting signs of certain conditions which affect both, especially abdominal pain or colic [9].

The anatomy of the equine digestive tract makes the equine more susceptible to colic than most other species. The equine stomachs relatively small compared to the size of the animal. Additionally, the horse has a one-way valve at the junction of the esophagus and stomach, i.e., movement of ingest is one-way to the lower GI tract that allowing movement of feed, water and gas in to the stomach but not out [10]. Feeding and spread rapidly involve all the small intestine, caecum and colon [11]. If there is a blockage further along in the small or large intestine, the one-way movement of ingest is blockage further alone in the small or large intestine, the one-way movement of ingest is blocked causing gastrointestinal upset and colic. The horse also has a large cecum, which is a blind sac, and a right ventral and left dorsal colon [4]. The entire digestive network is suspended and nourished by a thin membrane called the mesentery. Any malfunction, displacement, twisting, swelling, infection, or lesion of any part of this complex body system is what we recognize as colic. There seem to be countless situations which can precipitate colic. Many conditions causing colic become life- threatening in al relatively short period of time [12]. Donkeys show few overt sings of abdominal pain and colic 
may not be identified until the donkeys reach in terminal stage of disease [13].

Most consideration will be given to the treatment of the common gastrointestinal condition causing colic [11]. To understand the etiologies, make diagnosis and initiate appropriate treatments, veterinarian must first appreciate the clinically relevant aspect of equine gastro intestinal anatomy, the physiologic processes involved in movement of ingest and fluid along the gastrointestinal tract, and the extreme sensitivity of the horse to the deleterious effects of bacterial endotoxin that normal exist within the lumen of the intestine [14]. Many causes are not identified. Severe causes of colic are frequently identified at surgery or postmortem [10].

Therefore the objective of this study is to determine the prevalence of equine colic, and to investigate the major causal factors associated with the occurrence of the disease.

\section{Materials and Methods}

\section{Study area}

The study was conducted in the donkey sanctuary and SPANA operation areas in Ada's woreda and its rural villages, oromia national regional state. Both charities operate under the faculty of veterinary medicine of Addis Ababa University. The altitude of the study area is 1900 m.a.s.l. the area experiences an average rainfall of $850 \mathrm{~mm}$ and has got a mean annual temperature of $17^{\circ} \mathrm{C}$. the farmers in the vicinity of Debre Zeit follow a mixed crop- livestock farming system and a cereal legume cropping system. The heavy black day (Keticha) and high land pulses are grown. More over Debre Zeit and its surrounding (with in $50 \mathrm{~km}$ radius) has represented variable agro ecologic of the country [15].

\section{Study population}

The study populations are cases of donkeys and horses that were brought to charities clinics for support. Sampling was done irrespective of age and gender.

\section{Study design}

The study was descriptive case- series study.

\section{Study protocol}

Cases of donkeys and horses admitted to the donkey Sanctuary and SPANA clinic, respectively, were screened for colic study upon owners' compliant. Those cases ruled - in were subjected to thorough physical, clinical, and laboratory examinations. Feces and blood were samples collected.

Features recorded from the owner included sex, age, use, housing (indoor or outdoor), deworming history, change in deity and /or exercise regime prior to the colic. Recorded clinical features include nature of feces (normal, dry, absence, and diarrhoea), appetite, rectal temperature, pulse rate, abdominal pain (intermittent or continuous) abdominal auscultation, respiratory rate, mucous membrane colure, hematology (PVC) and microscopic examination of faecal sample. Body condition score (BCS) of the animals was determined based on the guidelines of NEWC.

\section{Data analysis}

The data obtained from case studies recorded on computer micro soft excel spread sheet and analyzed by using STATA 9.1 statistical software. A 95\% confidence level interval was used and significance level was at $\mathrm{p}$-value less than 0.05 . Data were presented in proportions, Tables and graphs.

\section{Results}

\section{The data is presented as follows}

There were 121 colic episodes in the population of 1336 ( 800 horses, 500 donkeys and 36 mules) examined between December 2009 and April 2010. The overall proportion of colic cases in both species was 93 (11.6\%) horses and 28 (5.6\%) donkeys. Thus, the overall proportion of colic cases in both horses and donkeys was 9.1\%. There was significantly $\left(\mathrm{x}^{2}=13.14 ; \mathrm{p}=0.0001\right)$ more colic cases in horses than donkeys. No mule was observed with colic case during the study period (Table 1).

\begin{tabular}{|c|c|c|c|c|c|}
\hline Species & $\begin{array}{l}\text { No. of } \\
\text { animals } \\
\text { observed }\end{array}$ & $\begin{array}{l}\text { No. } \\
\text { Colic } \\
\text { cases }\end{array}$ & Proportion (\%) & $x^{2}$ & P-Value \\
\hline Donkeys & 500 & 28 & 5.6 & \multirow{4}{*}{13.14} & \multirow{4}{*}{0.0003} \\
\hline Horses & 800 & 93 & 11.6 & & \\
\hline Mules & 360 & 2 & 0 & & \\
\hline Total & 1336 & 121 & 9.1 & & \\
\hline
\end{tabular}

Table 1: Total no. of equids admitted to both SPANA and donkey sanctuary clinics.

The monthly occurrence of colic cases is shown in Figure 1. In both donkeys and horses, more colic cases were observed in January while the smallest cases were recorded in March (donkey) and December (horse). The gender composition of donkey and horse colic cases revealed that out of the total cases, males comprise $86 \%(n=104)$ while females only $14 \%(\mathrm{n}=17)$ (Figure 2). Figure 3 depicts the age distribution of colic cases admitted to the clinic. The variation in distribution between ages was significantly $\left(x^{2}=10.3 ; p=0.016\right)$. In horses, the largest proportion $(43 \%)$ of colic cases were recorded in animals between 11 and 15 years of age whereas, in donkeys those between 6 and 10 years (39.3\%) were on top. In both species, animals $<5$ years of age comprised the least proportion of the overall colic cases (Figure 3). 
Citation: Tadesse B, Abera B (2018) Study on Major Causes of Equine Colic at the Donkey Sanctuary and SPANA Clinic in Bishoftu Town. J Vet

Page 3 of 7

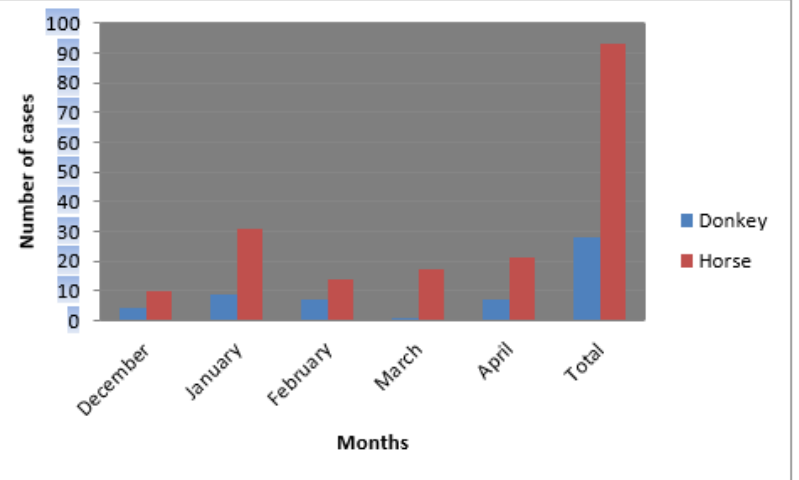

Figure 1: Colic cases admitted Dec to April 2010.

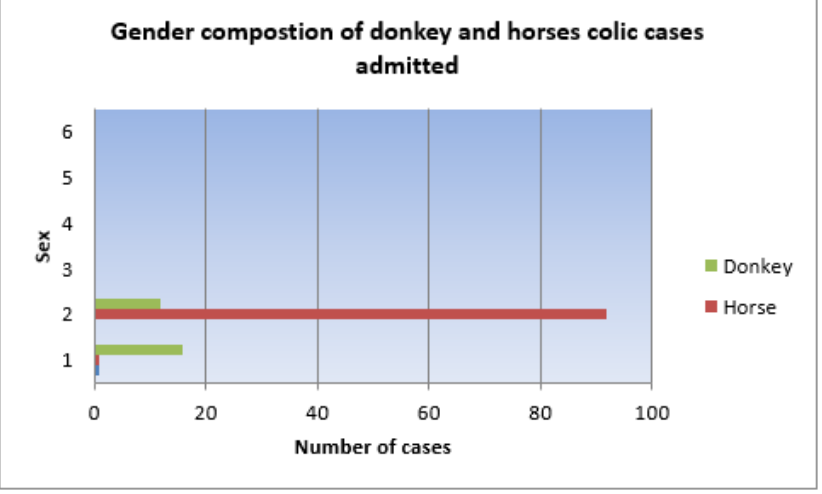

Figure 2: Gender composition of donkey and horse colic cases.

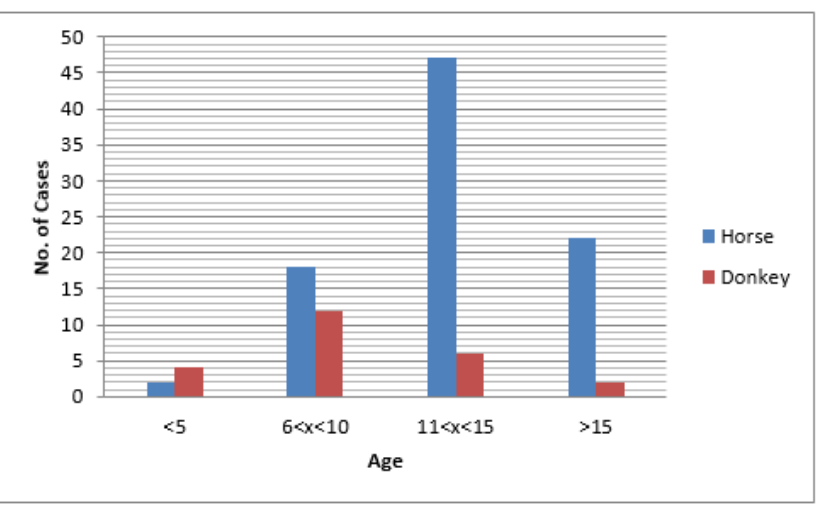

Figure 3: Age distribution of colic cases admitted to the clinic.

$\mathrm{Chi}^{2}=10.3 ; \mathrm{p}=0.016$.

Body condition score distribution of colic cases is presented in Figure 4. Among species poor body condition was highly observed in the horses. A greater proportion of horse (68.8\%) and donkey (57.1\%) colic cases were in poor body condition, having BCS less than 2 .

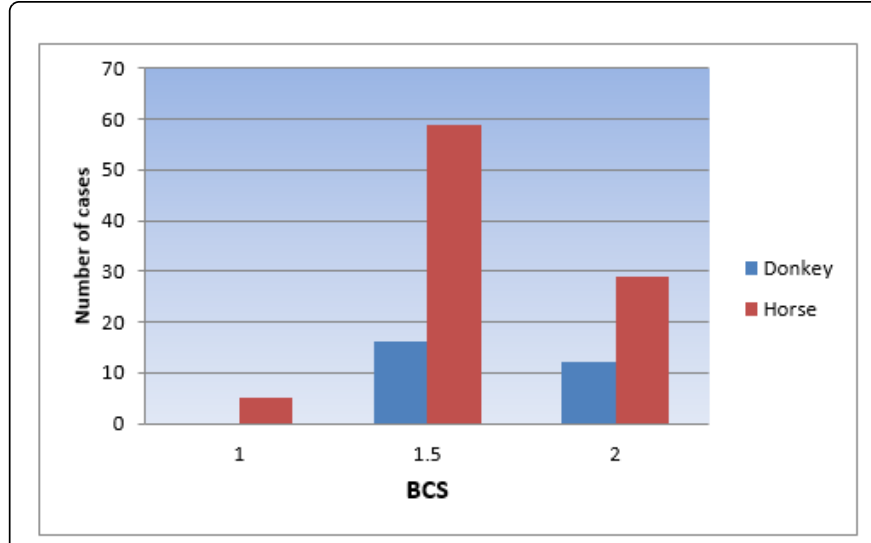

Figure 4: Conditional score of colic cases admitted.

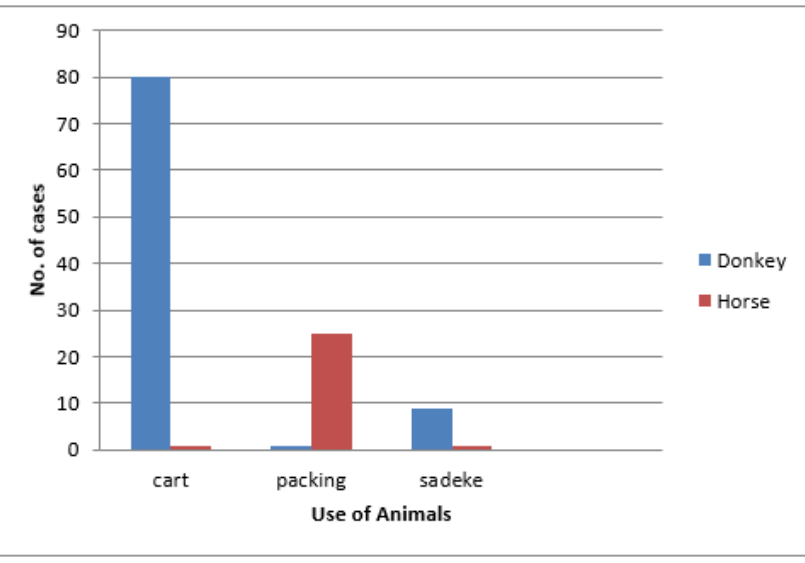

Figure 5: Purpose owners keep equids.

As shown in Figure 5, owners keep horses mainly for cart whereas donkeys for pack work purposes.

The overall proportion of colic cases in both species different between husbandry systems where $89(73.6 \%)$ were in door and $32(26.4 \%)$ outdoor. The proportion was significantly higher in door animals $73.6 \%(\mathrm{p}=0.001)$ than out door. But when the risk factors compared between species, in door was highly significant in the horses while outdoor highly significant in donkeys (Figure 6). 
Page 4 of 7

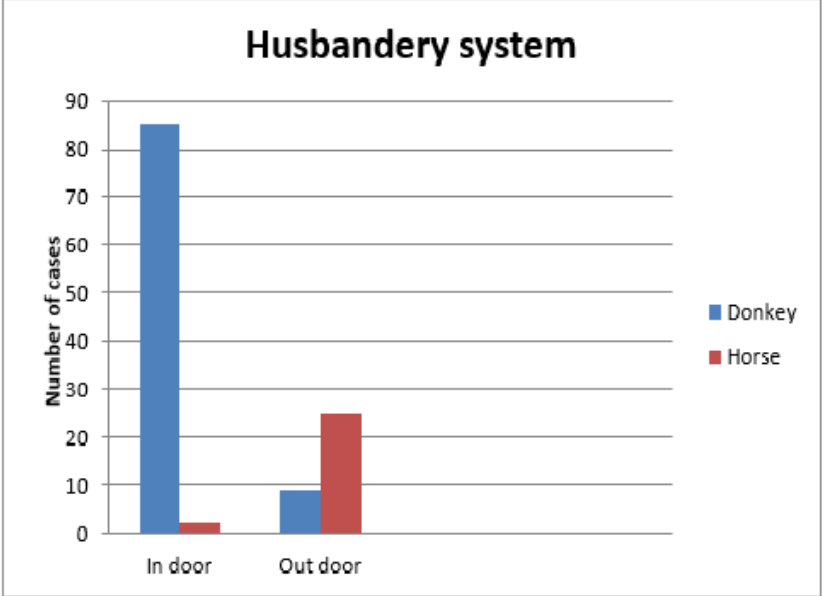

Figure 6: Husbandry system of equids.

Fisher's exact $=\mathrm{p}=0.001$

Feed change was highly associated with the occurrence of colic cases in both species (55.5\%), donkeys in particular. Among equids examined $108(89.3 \%)$ of the animals were not dewormed. Most of these animals were horses. Similarly, in fecal examination strongyles were observed more frequently in horses than donkeys $(\mathrm{p}=0.009)$. heavy work was equally important as a cause colic in both species ( $>0.006)$. Dental abnormality was observed more frequently in horse colic cases than donkeys $(p=0.007)$. horses in urban area were more vulnerable to colic tan donkeys while in the rural area, donkeys were more vulnerable than horses $(\mathrm{P}<0.00001$ in all the cases) (Table 2).

\begin{tabular}{|l|l|l|l|l|}
\hline Risk factors & Overall (\%) & Horse (\%) & Donkeys (\%) & p-value \\
\hline Feed change & 59.5 & 55.9 & 71.3 & 0.001 \\
\hline $\begin{array}{l}\text { Poor deworming } \\
\text { history }\end{array}$ & 89.3 & 88.2 & 42.9 & 0 \\
\hline Heavy work & 34.7 & 32.3 & 42.9 & 0.302 \\
\hline Enteriobithis & 6.6 & 3.2 & 17.9 & 0.006 \\
\hline $\begin{array}{l}\text { Dental } \\
\text { abnormality }\end{array}$ & 11.6 & 37.6 & 10.5 & 0.007 \\
\hline Strongyles & 60.3 & 66.7 & 39.3 & 0.009 \\
\hline Urban & 43.8 & 54.8 & 7.1 & 0 \\
\hline Rural & 56.2 & 45.2 & 92.9 & 0 \\
\hline
\end{tabular}

Table 2: Risk factors as associated with occurrence of colic cases in horses and donkeys.

The results of visual, physical and clinical examination of colic cases are presented in Table 3. Accordingly, decreased appetite, abdominal distension, dullness, continuous abdominal pain, decreased gut sound and congested mucous membrane were the common findings in donkey colic cases, in decreasing order of importance. In horsed Intermittent abdominal pain, increased gut sound, decreased apatite, and congested mucous membrane was observed in order of importance. Also, the average respiratory and pulse rates observed in both donkeys and horses were above the normal ranges given for these animals. However, the average temperature recorded in both spices was within the normal range.

\begin{tabular}{|l|l|l|}
\hline Observation & $\begin{array}{l}\text { Donkeys } \\
(\mathbf{n = 2 8})\end{array}$ & $\begin{array}{l}\text { Horses } \\
(\mathbf{n = 9 3})\end{array}$ \\
\hline Respiration rate, average(breath/min) & 29.8 & 26.8 \\
\hline Pulse rate, average (beat/min) & 63.5 & 55.5 \\
\hline Temperature in ${ }^{\circ}$ C, average & 37.4 & 38 \\
\hline Mean PCV-value & 50.5 & 41.3 \\
\hline Congestion of mucous membrane (\%) & 57.1 & 49.5 \\
\hline Abdominal auscultation (Gut sound) & & \\
\hline Increased (\%) & 10.7 & 68.8 \\
\hline Decreased (\%) & 67.9 & 26.9 \\
\hline Decreased appetite (\%) & 89.3 & 55 \\
\hline Abdominal distension (\%) & 89.3 & 25.6 \\
\hline Abdominal pain & & \\
\hline Intermittent (\%) & 10.7 & 77.4 \\
\hline Continuous (\%) & 10.771 .4 & 22.6 \\
\hline Dullness (\%) & 75 & - \\
\hline & & \\
\hline
\end{tabular}

Table 3: Results of physical clinical examination of colic suspected cases.

Based on the history, clinical signs, physical examination as well as laboratory findings the types of colic identified were classified as impaction colic, spasmodic colic, flatulent colic and undefined colic. Of these, impaction colic was the most frequently observed type in donkeys $(78.6 \%)$ and significantly higher $(\mathrm{p}<0.001)$ than that in horses (25.8\%) whereas the majority of horses $(66.7 \%)$ were affected with spasmodic colic (Table 4).

\begin{tabular}{|c|c|c|c|c|c|}
\hline $\begin{array}{l}\text { Types of } \\
\text { colic }\end{array}$ & $\begin{array}{l}\text { Total } \\
\text { proportion \% }\end{array}$ & $\begin{array}{l}\text { Horses } \\
\%\end{array}$ & Donkeys \% & $x^{2}$ & P-value \\
\hline $\begin{array}{l}\text { Impaction } \\
\text { colic }\end{array}$ & 38 & 25.8 & 78.6 & \multirow{4}{*}{25.5} & \multirow{4}{*}{0.00001} \\
\hline $\begin{array}{l}\text { Spasmodic } \\
\text { Colic }\end{array}$ & 51.2 & 66.7 & 0 & & \\
\hline Flatulent Colic & 5 & 0 & 21.4 & & \\
\hline $\begin{array}{l}\text { Undefined } \\
\text { Colic }\end{array}$ & 5.8 & 7.6 & 0 & & \\
\hline
\end{tabular}

Table 4: Types of colic commonly observed in horses and donkeys.

During the study period, large number of colic cases $(86.8 \%)$ were treated medically and only small proportion (13.3\%) of the cases were left due to the need for surgical intervention. However, surgical treatment was not carried out due to the poor prognosis after surgery and the need for great post operation care (Table 5).

\begin{tabular}{|l|l|}
\hline Type of management & Proportion (\%) \\
\hline
\end{tabular}




\begin{tabular}{|l|l|l|l|}
\hline & Total & Horses & Donkeys \\
\hline Medical & 86.8 & 92.5 & 67.9 \\
\hline Surgical & 13.3 & 7.5 & 32.1 \\
\hline
\end{tabular}

Table 5: Management of colic.

During the study period large number of animals (73.5\%) were recovered from the case after medical treatments and the fate of $20.7 \%$ cases was not known while only small number $(5.8 \%)$ of animals died without getting any treatment. All of the animals died were those surgery was recommended (Table 6).

\begin{tabular}{|c|c|c|c|}
\hline \multirow{2}{*}{ Prognosis } & \multicolumn{3}{|c|}{ Proportion (\%) } \\
\hline & Total & Horses & Donkeys \\
\hline $\begin{array}{l}\text { Recovered } \quad \text { after } \\
\text { treatment }\end{array}$ & 73.5 & 82.8 & 42.9 \\
\hline Death & 5.8 & & 25 \\
\hline Unknown & 20.7 & 17.2 & 32.1 \\
\hline
\end{tabular}

Table 6: Prognosis of colic cases.

\section{Discussion}

This study has identified that colic is one of the major health problems affecting equine in the study area. During the study period, colic cases were observed $n$ 9.1\% $(n=121)$ of the total 1336 equine presented to the donkey sanctuary and SPANA clinic. Colic was diagnosed in donkeys and horses only but no mule was observed with colic cases. This may be due to the very small number of mules brought to the clinic during the study period as well as the small population of these animals in the area and elsewhere in the county when compared with donkeys and horses [16]. In this study, the proportion of colic cases was significantly $(p=00003)$ higher in horses than in donkeys from the total number of colic patients. This finding is inconsistent with that of cox et al. [7], who reported that incidence of colic in donkeys was similar that in horses. Of the total colic cases. $86.8 \%$ were medically treated ( $81.9 \%$ horse and $19.2 \%$ donkey), while surgical procedure was recommended for only $13.3 \%$, all of which were donkeys. From those surgery recommended cases 66.7 percent were died. From 105 cases treated medically, $72.4 \%$ recovered while the fate of $34.3 \%$ was not known.

The case study conducted included almost all the important examinations which helped to known the severity of the cases and the prognosis of equips with abdominal pain history. During physical examination of the colic cases, the average respiratory rate observed in both donkeys $(29.8 \mathrm{r} / \mathrm{min})$ were above the normal limits for these animals. Similarly, the average pulse rate recorded in both donkeys $(63.5 \mathrm{~b} / \mathrm{min})$ and horses $(55.5 \mathrm{~b} / \mathrm{min})$ were also elevated. According to Beverly, the normal pulse and respiratory rates are $36+50$ beat $/ \mathrm{min}$ and 8-14 rate/min, respectively [12]. This finding concords with Cox et al. and Abrahamsen who stated that colic or abdominal pain have effect on cardiovascular status of the animals and increases In heart rate are generally attributed to pain $[7,17]$. The average temperature recorded in both species $\left(37.8^{\circ} \mathrm{C}\right.$ in donkeys and $38^{\circ} \mathrm{C}$ in horses) was within the normal range. The normal temperature of the equine ranges from $37.2-38.3^{\circ} \mathrm{C}[12]$. In this study, the mean PVC of donkeys (50.5\%) was higher than the normal value while that of horses (41.3\%) was within normal range. The normal PVC value for equine is 38-544 [12]. Most probably the increment of PVC-value in donkeys was due to impaction colic. This increment is attributed to increasing of circulating blood cell as a result of decreasing of plasma protein due to loss of fluid.

Age was significantly associated with colic in the current study. A sharp increase was seen up to 15 years of age and then the cases showed a tendency to decline toward the older animals. This finding is in agreement with many other studies $[8,18-20]$, which have reported that, when the age increases the animal found to be at risk of suffering with colic. In contrast to the present finding, white et al. has reported lack of association between age and colic [21]. The mean age of equips with colic in the present study was 12.6 year, which is slightly higher than mean age reported by the previous study [8].

Most of the colic cases (91\%) were observed in cart animals and only small proportion $(<10 \%)$ was seen in pack and saddle work type animals. The higher occurrence of colic in cart animals might be due provision of feed and water immediately after animals are released from the cart and before taking rest. The use of animals has also been considered as risk factor of colic in a previous study [19].

Feed change was implicated as a major risk factor for colic cases in the present study in that $71.3 \%$ donkeys and $55.9 \%$ horses had history of alteration in feed managements like sudden feed change, access to moldy type feed, grain over engorgement and irregular replacement of roughage with concentrates especially for those horses bought from rural areas and that have been kept in pasture. This finding is consistent with a number of previous studies $[18,19,22]$. According to these authors, feeds or feeding activity have long been blamed for the onset of colic and consequently, gradual change of diet to new type or amount of food recommended to prevent its occurrence.

The proportion of impaction colic was significantly higher in donkeys than in horses. This type of colic is associated mainly with feed change (over grain engorgement, low quality of feed and excess feeding without water), which was the most frequently observed risk factor in donkeys in this study. Another observation was obstruction due to enteroliths. Which were observed most of the time logged in the transverse or small colon during rectal examination. These manifested by sever acute abdominal pain, abdominal distention, decreased fecal passage, and weight loss. Similar observations were reported by other authors [4]. During the study period enteroliths were diagnosed in $6.6 \%$ of colic cases $(3.2 \%$ horses and $17.8 \%$ donkeys) by rectal examination. In agreement with this finding, many authors have shown that impaction colic was more common in donkeys that horse $[8,23,24]$. It has been stated that course roughage with low digestibility or particularly course fiber is the cause for impaction colic. This type of colic can easily be detected because of its common clinical sings like over distention of abdomen, dullness, decreased abdominal motility and any distended colon, caecum and pelvic flexure with dry faeces or hard stone like structure (enteroliths) [4]. In line with this abdominal distension, dullness and decreased abdominal motility was observed in $89.3 \%, 75 \%$ and $67.9 \%$ of donkey colic cases, respectively in the present study. Flatulent colic was observed in $21.4 \%$ of the aggected donkeys. It was seen in donkeys having a history of excess exposure to moldy feed. Donkey's abdomen was severely distended with high production of gas with absence of gut motility and deep dullness. Donkeys were unresponsive to any drug even though trocarisation of the caecum performed in order to release excessive gas produced in the caecum.

Unlike donkeys, the majority of horses (66.7\%) were affected with spasmodic colic. Spasmodic colic is suspected based on the clinical 
sign including fecal sample examination. Most of the time, this type of colic is common in pastured horses, which are exposed ton stronglyus larvae in the pasture, or due to cold water during hot time and sudden exercise. Audible gut sound heard from the distance, increased gut motility, and some times normal appetite were common clinical signs observed on horse with this types of colic. According to the Cox et al. spasmodic colic is commonly caused by high level of parasitic infection the horses [7], which is more prevanlent in pastured horse especially during rainy season when the strongylus larvae became dominant on the pasture [7], unless the owner of the animals is uses regular control methods of parasites. In the present study $89.3 \%$ of colic cases $(88.2 \%$ houses and $42.9 \%$ donkeys) had poor deworming history. In addition, strongyles were found in $66.7 \%$ horses and $39.3 \%$ donkeys. Moreover, $68.8 \%$ horses and $57 \%$ donkeys had poor body condition.

Dental abnormality may contribute to a decrease indigestibility of nutrients and may result in long fibers entering the colon. The previous studies have noted a possible relationship between dental disease and occurrence of colic $[25,26]$. This type of 1 abnormalities was observed in $37.6 \%$ horses and $10.5 \%$ donkeys in this study. Teeth abnormalities such as missing, loose, displaced teeth, and sharp teeth were reported as risk factors for colic case. When an animal has a dental problem it is unable to masticate the feed properly and consequently, predisposed to colic especially to the impaction type $[7,23,27]$.

\section{Conclusion and Recommendations}

Equine colic is a common clinical condition aggecting the health and survival of donkeys and horses at the donkeys sanctuary and SPANA clinic. Impaction colic was the most important colic identified in donkeys whereas; horses were mainly aggected with spasmodic colic. The major risk factors found assoiated with colic were age, feed change, parasite infestation and poor deworming history, enteroliths, heavy work and dental abnormalities. The common physical and clinical findings associated with colic cases in both horses and donkeys were rise in respiratory and pulse rates, congestion of mucous membrane, decreases appetite, abdominal distension, and in donkeys, higher mean PVC and dullness. Colic can range from mild to severe, but it should never be ignored. That's because many of the conditions that cause colic can become life threatening in a relatively short period of time. Only by quickly and accurately recognizing colic and seeking qualified veterinary help can the chance for recovery be maximized. Importantly, what this tells us is that, with conscientious care and management, we have the potential to reduce and control colic, the number one killer of horses.

Therefore, taking these in to account the following measures are recommended in order to reduce the occurrence of the disease.

- Owners should deworm their equine with in the proper time. Because, strategic deforming is important part of preventive health program.

- Feed small quantity of good qualities food at regular intervals.

- Maintaining adequate dental care that predispose to impaction colic due to poor digestion.

- Avoid watering immediately after work, especially cold water during hot time.

- The owners should be aware of relevant information about the horse when they want to buy, especially about feeding management and husbandry system, in order to take attention to change roughage by concentrate gradually for pastured horse where grass is common feed of them.
- Avoid feeding the equine moldy hay and feed that ripen from consumption of human.

- Avoid over packing or long distance without feed and water.

- Try to avoid any foreign material and alfalfa grass from the equine in order to prevent them from enteroliths.

- Good veterinary service also have important role in decreasing the economic loss of colic.

- Changes to new type of food should be taken gradually for newly bought horses especially those came from pasture where grass is common. It seems that more information on care, along with more knowledge of mixture of diet is needed on the farms in this study, although regular care.

- So, owners should be aware of the risk factors and prevention method. Educating the owners should be taken as the first measure to reduce colic cases as most of the suspected risk factors were related with un awareness of the owners.

\section{References}

1. Central statistical Agency (CSA) 2015/16 Federal democratic republic of Ethiopia Central statistical agency Agricultural sample survey. Volume ii Report on Livestock and livestock characteristics.

2. Wilson RT (1991) Equines in Ethiopia. In: Fielding, Pearso RA (eds.) Donkeys, mules and horses in tropical agricultural development for veterinary medicine. University of Edinburgh, pp: 15-166.

3. Svendsen PE (2008) The Professional Handbook of the donkey. 4th edn, Whittet Books Ltd, London, pp: 37-45.

4. Hallowell GD (2008) Retrospective study assessing efficacy of treatment of large colonic impactions. Equine Vet J 40: 411-413.

5. Shirazi-Beechey SP (2008) Molecular insights into dietary induced colic in the Horse. Equine Vet J 40: 414-421.

6. Solinger N, Sonea IM (2008) Distribution the neurokinin -1 receptor in equine Intestinal smooth muscle. Department of Biomedical Science.

7. Cox R, Praudman CJ, Trawford AF, Burden F, Pinchbeck GL (2007) Epidemiology of impaction colic in donkeys in the Uk. BMC Vet Res 3: 1.

8. Reeves MJ, Salman MD, Smith G (1996) Risk factors for Equine acute abdominal disease (colic). Results from a multi -center- control study. Prev Vet Med 26: 285-301.

9. Duffield HF, Bell N, Henson FMD (2002) The common presenting signs and causes of colic in the donkey. In: Proceedings of the 41st British Equine Veterinary Association Congress, Glasgow, UK, p: 214.

10. Colahan PT (1999) Equine Medicine and Surgery. 5th edn, USA, pp: 10-22.

11. Reed S (2004) Equine Internal Medicine. 2nd edn, USA, pp: 22-933.

12. Beverly JW (2001) Equine Colic: Double Ranch-Tack, Personal Service Quality Saddel.

13. Lakia MD, Von Rosebeng CA (1995) Modified colotomy-Lavage technique to relieve impactions. Equine practice, Ocala, Florida, pp: 13-15.

14. Radostits OM, Gay CC, Hinchcliff KW, Constable PD (2007) Veterinary Medicine: A text book of the disease of cattle, horse, sheep, pig and goat. 10th edn, Bailliere Tidal, London, p: 1575.

15. Debre Zeit (2005) Agricultural research data book, New Delhi, India.

16. Food and Agricultural Organization (FAO) of the United Nation (1993) Agrostat data. Statistics division, Rome, Italy.

17. Abrahamsen EJ (2009) Option for managing colic pain. Hagyard equine medical institutes management seminar.

18. Tinker MK, White NA, Lessard P, Thatcher CD, Pelzer KD, et al. (1997) Prospective study of equine colic risk factors. Equine Vet J 29: 454-458.

19. Cohen ND, Gibbs PG, Woods AM (1999) Dietary and other management factors associated with colic in horses. J Am Vet Med Assoc 215: 667-673. 
Citation: Tadesse B, Abera B (2018) Study on Major Causes of Equine Colic at the Donkey Sanctuary and SPANA Clinic in Bishoftu Town. J Vet Sci Technol 9: 504. doi:10.4172/2157-7579.1000504

Page 7 of 7

20. Kaneene JB, Miller R, Ross WA, Gallagher K, Martenuik J, et al. (1997) Risk factors for colic in the Michigan (USA) Equine population. Prev Vet Med 30: 23-36.

21. White NA (2007) Colic prevalence, Risk factors and Prevention. Advances in Equine Nutrition 4: 313.

22. Hudson JM, Cohen ND, Gibbs PG, Thompson JA (2007) Feeding practices associated with colic in horses. J Am Vet Med Assoc 219: 1419-1425.

23. Cox R, Burden F, Gosden L, Praudman C, Trawfored A, et al. (2009) Case control study to investigate risk factors for impaction colic in donkey in the UK. Prev Vet Med 92: 179-187.
24. Byars T (1993) Management of impaction colic in the horses. Nandino bowevared 15: 30

25. Duffield HF, Henson FMD (2002) Factors associated with impactive colic in the donkey. Proceedings of the 7th International equine research symposium, Manchester, UK, p: 122.

26. Brosnahan MM, Paradis MR (2003) Demographic and clinical characteristics of geriatric horses: 467 cases (1989-1999). J Am Vet Med Assoc 223: 93-98.

27. White JLN (1997) Rick factor associated with colic, in current Therapy in Equine Medicine. 4th edn. Philadelphia, WB Saunders Co., pp: 174-179. 